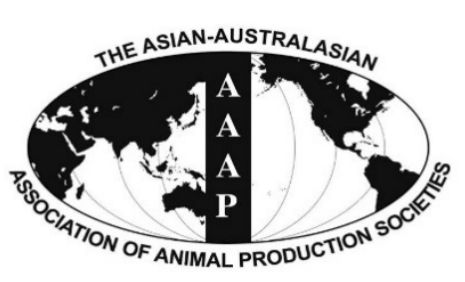

Open Access

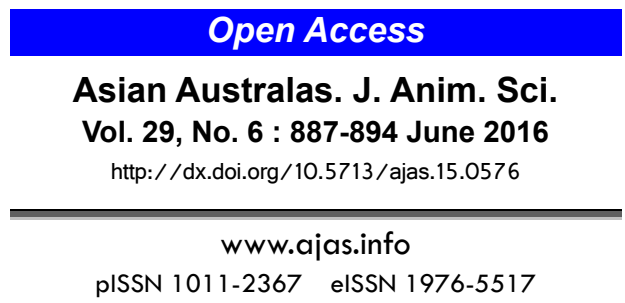

\title{
Effects of Furnished Cage Type on Behavior and Welfare of Laying Hens
}

\author{
Xiang Li, Donghua Chen, Jianhong $\mathrm{Li}^{1}$, and Jun Bao* \\ College of Animal Science and Technology, Northeast Agricultural University, Harbin 150030, China
}

\begin{abstract}
This study was conducted to compare the effects of layout of furniture (a perch, nest, and sandbox) in cages on behavior and welfare of hens. Two hundred and sixteen Hyline Brown laying hens were divided into five groups (treatments) with four replicates per group: small furnished cages (SFC), medium furnished cages type I (MFC-I), medium furnished cages type II (MFC-II), and medium furnished cages type III (MFC-III) and conventional cages (CC). The experiment started at 18 week of age and finished at 52 week of age. Hens' behaviors were filmed during the following periods: 8:00 to 10:00; 13:00 to 14:00; 16:00 to 17:00 on three separate days and two hens from each cage were measured for welfare parameters at $50 \mathrm{wk}$ of age. The results showed that feeding and laying of all hens showed no effect by cage type ( $>0.05$ ), and the hens in the furnished cages had significantly lower standing and higher walking than CC hens $(\mathrm{p}<0.05)$. The birds in MFC-III had significant higher preening, scratching and feather-pecking behavior than in the other cages $(p<0.05)$. No difference in nesting behavior was found in the hens between the furnished cages $(p>0.05)$. The hens in MFC-I, -II, and -III showed a significant higher socializing behavior than SFC and CC $(\mathrm{p}<0.05)$. The lowest perching was for the hens in SFC and the highest perching found for the hens in MFC-III. Overall, the hens in CC showed poorer welfare conditions than the furnished cages, in which the feather condition score, gait score and tonic immobility duration of the hens in CC was significantly higher than SFC, MFC-I, MFC-II, and MFC-III $(\mathrm{p}<0.05)$. In conclusion, the furnished cage design affected both behavior and welfare states of hens. Overall, MFC-III cage design was better than SFC, MFC-I, and MFC-II cage designs. (Key Words: Behavior, Welfare, Furnished Cage Design, Hen)
\end{abstract}

\section{INTRODUCTION}

Furnished cages were developed in response to criticisms about the conventional battery-cage due to its confinement of laying hens in commercial egg production. Furnished cages are typically equipped with a nest box, perch, and dust-bathing area, thereby providing more chances for laying hens to perform more natural behavior such as perching and sandbathing than the conventional cages (CC) (Cordiner and Savory, 2001; Albentosa and Cooper, 2004; Wall et al., 2004). Moreover, hens in furnished cages perform more behavioral changes or posture changes, and more preening behavior (Pohle and Cheng, 2009). So the furnished cages are used as an

\footnotetext{
* Corresponding Author: Jun Bao. Tel: +86-180-45170099, Fax: +86-451-55190099, E-mail: jbao@neau.edu.cn

${ }^{1}$ College of Life Science, Northeast Agricultural University, Harbin, 150030, China.

Submitted Jul. 7, 2015; Revised Aug. 29, 2015; Accepted Sept. 11, 2015
}

alternative system to the $\mathrm{CC}$ production system. Although furnished cages do allow caged hens to engage in a larger array of natural behavior patterns, the size and design of furnished cages vary and space allowance in both the horizontal and vertical dimensions of the enclosure impedes movement, limiting important natural behavior (Blokhuis et al., 2007). As well, the restrictive design of furnished cages prevents the hens from exercising, leading to skeletal weakness (Blokhuis et al., 2007). There are many physical factors influencing hens' activity in furnished cages, such as stocking density (Shimmura et al., 2007), litter materials (Guinebretière et al., 2014), and even bird age (Nicol et al., 2001). One study reported that hens performed $26.7 \%$ of dust bathing in the area provided within the enclosure (Lindberg and Nicol, 1997); while another study of the same type of furnished cage showed that all dust bathing occurred in the dust bath (Appleby and Hughes, 1995). The use of the dust bathing area by hens was found to be highly variable in furnished cages with some hens visiting the dust 
bath a great deal and others not at all (Wall et al., 2008). This may indicate that the location or design of the dust bath in furnished cages is somehow inadequate. Studies also have shown that hens prefer perches that are placed higher off the ground than those that are closer to the floor (Struelens et al., 2008). In a cage, however, this is severely limited by the distance from the floor to the ceiling. Hens use perches of different heights for different types of behavior, tending to stand or walk on lower perches, while sitting or resting on higher ones (Struelens et al., 2008). Both lower and higher perches can be offered in cage-free environments to accommodate this behavioral differentiation, whereas most available furnished cage system designs do not provide multi-level perches.

In addition, previous studies show the furnished cages can play an important role in improving hens' welfare, by decreasing fear, aggression and pecking behavior, and increasing the bone density compared to $\mathrm{CC}$ cages (Gvaryahu et al., 1994). Besides, furnished cages can also improve feather and claw conditions compared to $\mathrm{CC}$ cages (Barnett and Cronin, 2005). It is reported that furnished cages can improve the welfare of laying hens, but differences are found in different furnished cages (Pohle and Cheng, 2009). This study was conducted to compare the effects of furnished cages with different furniture design such as the location of a perch, dust bathing and nest box in a cage on behavior and welfare of laying hens, and to provide additional information for better design of furnished cages.

\section{MATERIALS AND METHODS}

\section{Designs of furnished cages}

In this study four types of furnished cages: i) small furnished cage (SFC, Figure 1) designed according to the criterion of European Union (Directive, 1999); ii) medium

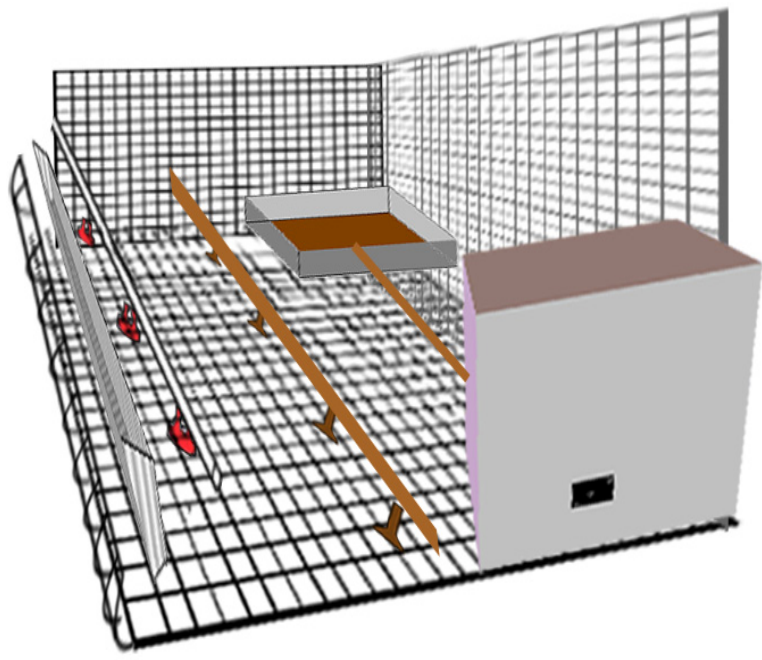

Figure 1. Stereogram of small furnished cage (SFC).

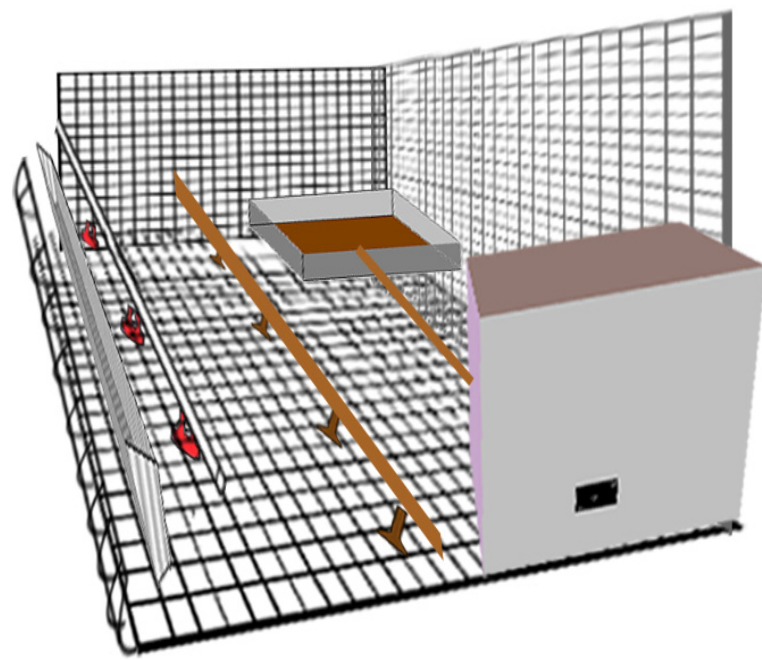

Figure 2. Stereogram of middle furnished cage type-I (MFC-I).

size furnished cage I (MFC-I, Figure 2); iii) medium size furnished cage II (MFC-II, Figure 3) and iii) medium size furnished cage III (MFC-III, Figure 4) were designed, and CC (commercial type) was taken as control. The information on cage dimensions, furniture locations, and stocking density are given in Table 1.

\section{Animal management and treatments}

In this study, 216 Hyline Brown laying hens were randomly chosen from the same commercial flock of 2,000 hens at the 16 weeks of age. Experimental birds were divided into five groups or cages (SFC, MFC-I, MFC-II, and MFC-III and CC) with four replicates per group. Experiment started at 18 weeks of age and lasted to 52 weeks. All the hens were housed in the same test room and received an corn-soybean based feed (metabolizable energy, $11.10 \mathrm{MJ} / \mathrm{mol}$, crude protein, $16.50 \%$ ) and were fed twice a day at 7:00 and 15:00. Water was available ad libitum in all

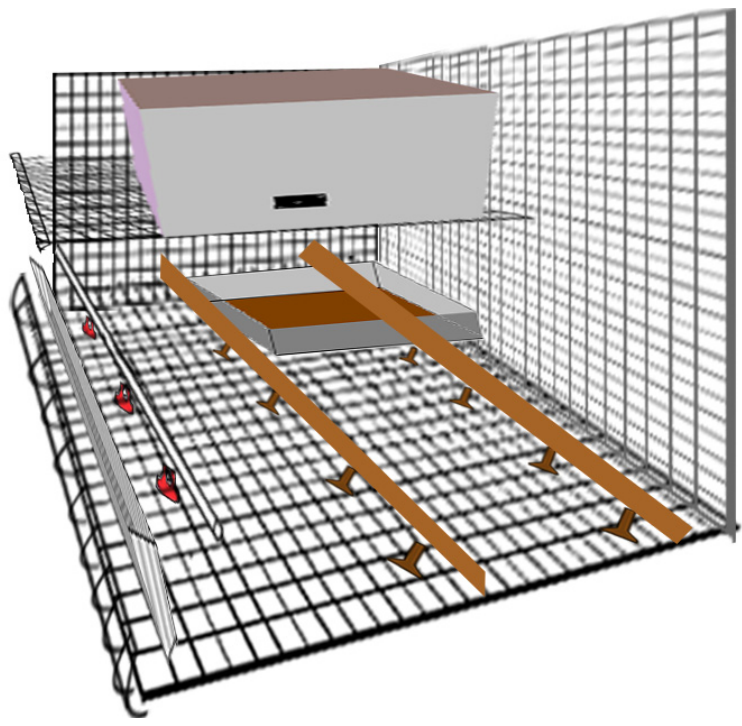

Figure 3. Stereogram of middle furnished cage type-II (MFC-II). 


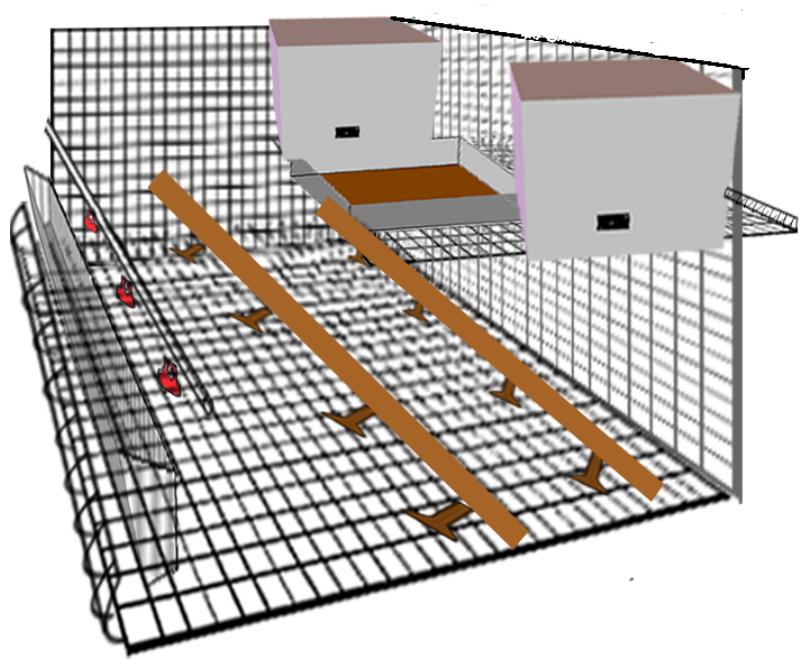

Figure 4. Stereogram of middle furnished cage type-III (MFCIII).

cages. Ambient temperature was maintained at 18 to $20^{\circ} \mathrm{C}$ and relative humidity was maintained at $50 \%$ to $65 \%$ during day. Light schedule was $16 \mathrm{~h} \mathrm{L:8} \mathrm{h} \mathrm{D} \mathrm{with} \mathrm{light} \mathrm{onset} \mathrm{at}$ 4:30 am. Mechanical ventilation was used to control the dust and ammonia concentration.

\section{Measurements}

Behavior measuring: Behavioral observation was conducted by one observer throughout the whole experiment. Behavioral data were collected using 10 video cameras (FS-EH303, Shenzhen Feihongxin technology company, Shenzhen, China) with infrared light sources switched on during night period (18:00 to 08:00). Each camera was fixed on the opposite site of the cages to record two cages. For behavioral observation, in each cage three hens were randomly selected and individually marked by spraying dyes of different colors (black, white or blue) on their body. Hens' behavior was filmed during the following periods: $8: 00$ to $10: 00 ; 13: 00$ to $14: 00 ; 16: 00$ to $17: 00$ on Wednesdays of $32 \mathrm{w}, 42 \mathrm{w}$, and $52 \mathrm{w}$. Video recording was analyzed by scan sampling and instantaneous sampling for the general behavior (Martin and Bateson, 2007). The general behaviors were divided into two categories. One is state behaviors including feeding, standing lying, walking, perching, using dust bath and using nesting box. Another is event behaviors including drinking, preening, staring pecking, head-shaking, feather-pecking, dust-pecking, and socializing. The behavioral category and definitions are presented in Table 2. There were four hours in total for behavioral observation per watch. For scan sampling, the time used for each scam sampling was $5 \mathrm{~min}$. therefore, there were 48 scan samples collected for each observation day. For instantaneous sampling, the occurrence of any event behaviors described in Table 2 was recorded during 4 hours observation over three observation periods.

Welfare conditions: Welfare parameters were assessed by selecting two birds randomly from each cage at $50 \mathrm{w}$ of age by an experienced observer. The parameters included feather condition, gait score, claw condition, keel bone deformation (KBD) and tonic immobility duration. The scoring system was defined as follows:

Feather condition score: the score for feather condition was assessed on eight parts of body: head, neck, back, tail, wing, breast, vent, and leg. The scoring criterion for each part was classified as 0 score: feather was perfect with no damage; 1 score: feather was slight damaged but skin was all covered; 2 score: feather was damaged and the exposed area of skin was less than $1 \mathrm{~cm} \times 1 \mathrm{~cm} ; 3$ score: feather was damaged and the exposed area of skin was larger than 1 $\mathrm{cm} \times 1 \mathrm{~cm}$.

Table 1. Design parameters of different models of cages

\begin{tabular}{|c|c|c|c|c|c|c|}
\hline & Type & SFC & MFCI & MFCII & MFCIII & $\mathrm{CC}$ \\
\hline & Cage dimension $(\mathrm{cm})$ & $120 \times 50 \times 45$ & $192 \times 62.5 \times 45$ & $160 \times 75 \times 70$ & $160 \times 75 \times 70$ & $192 \times 33 \times 35$ \\
\hline \multirow[t]{5}{*}{ Upper tier } & & & & $32 \times 75 \times 35$ & $160 \times 30 \times 35$ & \\
\hline & Number of hens & 6 & 12 & 12 & 12 & 12 \\
\hline & Housing density (hens $/ \mathrm{m}^{2}$ ) & 10 & 10 & 10 & 10 & 18.9 \\
\hline & Area $\left(\mathrm{cm}^{2}\right)$ & 6,000 & 12,000 & 12,000 & 12,000 & 6,336 \\
\hline & Average area $\left(\mathrm{cm}^{2} /\right.$ per hen $)$ & 1,000 & 1,000 & 1,000 & 1,000 & 528 \\
\hline \multirow[t]{3}{*}{ Total space } & Housing density (hens $/ \mathrm{m}^{2}$ ) & 10 & 10 & 8.33 & 7.14 & 18.9 \\
\hline & Total area $\left(\mathrm{cm}^{2}\right)$ & 6,000 & 1,2000 & 14,400 & 16,800 & 6,336 \\
\hline & Average area $\left(\mathrm{cm}^{2} /\right.$ per hen $)$ & 1,000 & 1,000 & 1,200 & 1,400 & 528 \\
\hline \multirow[t]{6}{*}{ Furnisher } & Nest dimension $(\mathrm{cm})$ & $24 \times 50 \times 27$ & $38.4 \times 62.5 \times 45$ & $32 \times 75 \times 35$ & $40 \times 30 \times 35(\times 2)$ & \\
\hline & Nest allowance $\left(\mathrm{cm}^{2} /\right.$ per hen $)$ & 200 & 200 & 200 & 200 & \\
\hline & Dustbath box $(\mathrm{cm})$ & $24 \times 50 \times 5$ & $20 \times 60 \times 5$ & $32 \times 75 \times 5$ & $80 \times 30 \times 5$ & \\
\hline & Dustbath allowance $\left(\mathrm{cm}^{2} /\right.$ per hen $)$ & 200 & 100 & 200 & 200 & \\
\hline & Perch length $(\mathrm{cm})$ & 96 & $133.6 \times 2$ & $128 \times 2$ & $160 \times 2$ & \\
\hline & Perch allowance $(\mathrm{cm} /$ per hen $)$ & 16 & 22.3 & 21.3 & 26.7 & \\
\hline
\end{tabular}

SFC, small furnished cages; MFC, medium furnished cages; $\mathrm{CC}$, conventional cages. 
Table 2. Behavioral categories and definitions

\begin{tabular}{|c|c|}
\hline Behavioral categories & Definitions \\
\hline Feeding & Hen directs its beak to feed trough and carries out pecking or eating, once or repeatedly \\
\hline Dust bath use & All behaviors exhibited when the hens are in the dustbath box \\
\hline Perching & All behaviors exhibited when the hens are on perches \\
\hline Nesting box use & All behaviors exhibited when the hens are in the nest \\
\hline Standing & Both legs are straightened on the floor \\
\hline Lying on floor & Hens' abdomen contacts with the floor and both legs are twisted under the body \\
\hline Walking & Hen raises one of its legs with the other leg standing on floor and moves forward \\
\hline Drinking & Hen directs its beak to nipple drinker and raises its head when getting water \\
\hline Preening & $\begin{array}{l}\text { Hen directs its beak to its own plumage of several body parts(thorax, abdomen, shoulder, interior and exterior } \\
\text { wings, rumps, back and cloaca) and carries on pecking, nibbling, combing or rotating movements, once or } \\
\text { repeatedly (Pickel et al., 2010) }\end{array}$ \\
\hline Staring & Hens' head stayed immobile with its eyes looking at an object while standing \\
\hline Beak-wiping & Hen wiping its beak on cage or feeder \\
\hline Head-shaking & Hen shaking her head repeatedly \\
\hline Scratching & Hen directs its claw to the floor and rubbing it repeatedly \\
\hline Feather-pecking & Hen pecking or pulling others' feather \\
\hline Socializing & $\begin{array}{l}\text { Behaviors happened between two or more hens including pecking (beak-peck, head-peaking, and claw-pecking) } \\
\text { or contacting (body to body contacting) }\end{array}$ \\
\hline
\end{tabular}

Gait score: The test hens were put into a dark and quiet room for observation and recording the gait score. The score for gait condition was defined as follow: 0: hen can walk normally and maintain good balance; 1: hen has slight gait fault; 2: hen has obvious gait fault, such as lameness; 3 : hen can walk only under intense stimulation.

Claw condition score: the hen was held gently by one person, and another person examined the claw condition. The criterion of claw score was defined as follows. 0: claw was intact, clear with no damage; 1: claw was intact and the contaminated area of skin was less than $50 \% ; 2$ : claw was intact and the contaminated area of skin was more than $50 \%$; 3: claw was damaged and not intact.

Keel bone deformation score: the hen was held gently by one person, and another person examined and palpated the keel bone. The KBD was considered by deviation from straight and the criterion of KBD was defined as follows. 0: keel bone was intact with no deformation; 1: keel bone was slightly deformed, the extent of deformation was less than $10 \% ; 2$ : keel bone was deformed, the extent of deformation was $10 \%$ to $50 \%$; 3 : keel bone was deformed, the extent of deformation was more than $50 \%$;

Tonic immobility duration: the hens were put into a quiet room, and fixed into a U-groove which was made of the plastic pipe with $15 \mathrm{~cm}$ in diameter. The hens were held gently and placed on their back for $15 \mathrm{~s}$. Then the handler removed his hands from the hens, and the time was recorded until the hens righted themselves.

\section{Statistical analyses}

Data were analyzed using the analysis of variance procedure of the SAS package (SAS 8.2). The state behaviors were presented as a percentage of the total observations, and the event behaviors were presented as the frequency of the occurrences per hour. All behavioral data were tested for normality, and the data for event behaviors were square root +0.5 transformed before analyzing. Duncan test was used for multiple comparisons. Data were presented as means \pm standard deviation. Probability values less than 0.05 were considered as significant.

\section{RESULTS}

\section{Effects of furnished cages on behaviors}

The results of the effect of cage type on hens' behavior are given in Table 3. Feeding and lying of all hens showed no effect by cage type $(p>0.05)$. The hens in the furnished cages had significantly lower standing than CC hens $(p<0.05)$, while their walking was significantly higher than $\mathrm{CC}$ hens $(\mathrm{p}<0.05)$ with the highest walking found for SFC hens. In this study, higher dust bathing was found for the hens in MFC-I than in SFC $(p<0.05)$, and the lowest perching was for the hens in SFC, which was significantly lower than the hens in MFC-I, -II, and -III with the highest perching found for the hens in MFC-III. No difference in nesting behavior was found between the furnished cages $(\mathrm{p}>0.05)$.

The birds in MFC-III had significant higher preening than other cages $(p<0.05)$. Also the hens in MFC-I and -II tended to show higher preening than SFC and CC, but not significant. In staring behavior only a significant difference $(p<0.05)$ was found in the hens between SFC and MFC-III in which the hens showed the highest preening. The hens in MFC-I showed significantly higher head-shaking behavior 
Table 3. Comparison of behaviors of the hens between $\mathrm{CC}$ and the furnished cages

\begin{tabular}{lccrcc}
\hline & CC & \multicolumn{1}{c}{ SFC } & MFCI & MFCII & MFCIII \\
\hline State behavior (\%) & & & & & \\
Feeding & $38.42 \pm 26.36$ & $38.26 \pm 13.65$ & $31.52 \pm 11.22$ & $33.67 \pm 12.57$ & $24.48 \pm 12.53$ \\
Dust bath using & - & $3.15^{\mathrm{b}} \pm 4.62$ & $11.92^{\mathrm{a}} \pm 4.99$ & $8.14^{\mathrm{a}} \pm 4.23$ & $7.75^{\mathrm{ab}} \pm 4.93$ \\
Perching & - & $1.32^{\mathrm{c}} \pm 1.38$ & $14.21^{\mathrm{b}} \pm 7.47$ & $16.59^{\mathrm{ab}} \pm 7.35$ & $22.64^{\mathrm{a}} \pm 10.23$ \\
Nesting-box using & - & $2.08 \pm 3.96$ & $1.40 \pm 1.74$ & $2.00 \pm 2.61$ & $4.34 \pm 3.53$ \\
Standing & $48.33^{\mathrm{a}} \pm 20.51$ & $28.49^{\mathrm{b}} \pm 7.32$ & $26.88^{\mathrm{b}} \pm 9.35$ & $23.09^{\mathrm{b}} \pm 6.29$ & $24.28^{\mathrm{b}} \pm 10.38$ \\
Lying & $9.22 \pm 5.65$ & $8.22 \pm 9.29$ & $3.45 \pm 2.78$ & $4.22 \pm 3.91$ & $5.29 \pm 4.45$ \\
Walking & $4.02^{\mathrm{c}} \pm 2.89$ & $18.46^{\mathrm{a}} \pm 8.02$ & $10.61^{\mathrm{b}} \pm 3.26$ & $12.29^{\mathrm{ab}} \pm 1.58$ & $11.19^{\mathrm{b}} \pm 4.12$ \\
Event behavior (n/h) & & & & & \\
Preening & $6.00^{\mathrm{bc}} \pm 5.40$ & $3.60^{\mathrm{c}} \pm 1.80$ & $10.2^{\mathrm{bc}} \pm 4.20$ & $9.60^{\mathrm{bc}} \pm 4.20$ & $21.0^{\mathrm{a}} \pm 14.4$ \\
Staring & $21.0^{\mathrm{ab}} \pm 14.4$ & $7.20^{\mathrm{b}} \pm 3.60$ & $20.4^{\mathrm{ab}} \pm 1.80$ & $17.4^{\mathrm{ab}} \pm 4.80$ & $29.4^{\mathrm{a}} \pm 17.4$ \\
Head-shaking & $4.80^{\mathrm{ab}} \pm 6.60$ & $1.20^{\mathrm{b}} \pm 1.80$ & $8.40^{\mathrm{a}} \pm 5.40$ & $5.40^{\mathrm{ab}} \pm 4.80$ & $3.60^{\mathrm{ab}} \pm 2.40$ \\
Scratching & $0.60^{\mathrm{b}} \pm 0.60$ & $1.20^{\mathrm{b}} \pm 1.20$ & $0.60^{\mathrm{b}} \pm 0.60$ & $1.80^{\mathrm{b}} \pm 0.60$ & $7.20^{\mathrm{a}} \pm 5.40$ \\
Feather-pecking & $1.80^{\mathrm{b}} \pm 1.80$ & $3.00^{\mathrm{b}} \pm 3.60$ & $5.40^{\mathrm{b}} \pm 2.40$ & $4.80^{\mathrm{b}} \pm 1.80$ & $1.20^{\mathrm{a}} \pm 0.78$ \\
Socializing & $2.00^{\mathrm{b}} \pm 0.50$ & $3.00^{\mathrm{b}} \pm 2.40$ & $8.40^{\mathrm{a}} \pm 1.20$ & $9.60^{\mathrm{a}} \pm 3.00$ & $6.60^{\mathrm{a}} \pm 4.20$ \\
\hline
\end{tabular}

CC, conventional cage; SFC, small furnished cage; MFCI, middle furnished cage type I; MFCII, middle furnished cage type II; MFCIII, middle furnished cage type III.

Different superscripts in a row indicate significant difference at $\mathrm{p}<0.05 ; \mathrm{n}=4$ replicates for each cage.

than SFC $(\mathrm{p}<0.05)$, while the hens in MFC-III had a significant higher scratching and feather-pecking behavior than the other cages $(p<0.05)$. The hens in MFC-I, -II, and III showed a significant higher socializing behavior than SFC and CC $(p<0.05)$.

\section{Effects of furnished cages on welfare conditions}

The results of the effects of the cage type on welfare conditions were given in Table 4. Overall, the hens in CC showed poorer welfare conditions than the furnished cages, in which the feather condition score, gait score and tonic immobility duration of the hens in $\mathrm{CC}$ was significantly higher than SFC, MFC-I, MFC-II, and -III $(\mathrm{p}<0.05)$. The KBD score was also higher than the other furnished cages, despite the difference not reaching significance. Furthermore, the results showed that claw score of the hens in $\mathrm{CC}$ was not different from that in SFC but significantly lower than that in MFC-I $(\mathrm{p}<0.05)$. While compared with MFC-I and -II, higher claw score was found for the hens in $\mathrm{CC}$ although it was not significant.
Among the furnished cages, feather condition score in MFC-I was significantly higher than MFC-II $(\mathrm{p}<0.05)$ and MFC-III $(p<0.01)$ with the lowest feather condition score was for MFC-III. Claw score for the hens in MFC-I was significantly higher than SFC, MFC-II $(\mathrm{p}<0.05)$ and MFCIII $(p<0.01)$ and the lowest score was also found for the hens in MFC-III. While gait score was not significantly different between the furnished cages ( $p>0.05)$. Similarly, no difference was found for KBD score between the furnished cages. Although tonic immobility duration was found higher for the hens in MFC-II than other furnished cages, the difference was not significant.

\section{DISCUSSION}

\section{The effects of furnished cage type on behaviors}

The behavioral changes of animals can be considered as an indicator of adaptability to environment (Dawkins, 1999). Hens are social animals and always live together in natural conditions. In $\mathrm{CC}$, hens still perform sham dustbathing and

Table 4. Welfare measurements of laying hens with different cage designs at $50 \mathrm{wk}$ of ages ${ }^{1,2}$

\begin{tabular}{lccccc}
\hline & \multicolumn{5}{c}{ Category cage type } \\
\cline { 2 - 6 } & CC & SFC & MFC-I & MFC-II & MFC-III \\
\hline Feather score & $3.37^{\mathrm{a}}$ & $1.87^{\mathrm{ab}}$ & $2.62^{\mathrm{a}}$ & $1.20^{\mathrm{bc}}$ & $0.88^{\mathrm{c}}$ \\
Claw score & $0.89^{\mathrm{bc}}$ & $1.00^{\mathrm{b}}$ & $2.00^{\mathrm{a}}$ & $0.38^{\mathrm{bc}}$ & $0.33^{\mathrm{c}}$ \\
Gait score & $1.25^{\mathrm{a}}$ & $0.45^{\mathrm{b}}$ & $0.50^{\mathrm{b}}$ & $0.37^{\mathrm{b}}$ & $0.38^{\mathrm{b}}$ \\
Keel bone deformation score & 0.87 & 0.37 & 0.62 & 0.25 & 0.38 \\
Tonic immobility duration (s) & $69.88^{\mathrm{a}}$ & $49.63^{\mathrm{b}}$ & $53.87^{\mathrm{b}}$ & $49.38^{\mathrm{b}}$ & $45.12^{\mathrm{b}}$ \\
\hline
\end{tabular}

CC, conventional cage; SFC, small furnished cage; MFCI, middle furnished cage type I; MFCII, middle furnished cage type II; MFCIII, middle furnished cage type III.

${ }^{1}$ Higher scores indicate poorer condition. ${ }^{2} \mathrm{n}=8$.

${ }_{a, b, c}$ Different superscripts in a column indicate significant difference at $\mathrm{p}<0.05$. 
nesting behavior, but it frustrates them (Weeks and Nicol, 2006). In furnished cages, however, hens are allowed to perform natural behaviors such as perching, nesting, and dustbathing due to the provision of perch, nest and dustbath (Lindberg and Nicol, 1997; Cordiner and Savory, 2001). In this study the design of furnished cage was found to affect perching, dustbathing and nesting, and hens in larger furnished cages (MFC-I, -II, and -III) showed more perching than in SFC. This may be attributed to different perch allowance per bird in each type of cage where each SFC hen had only $16 \mathrm{~cm}$ perch allowance compared with $22.3 \mathrm{~cm} /$ hen for MFC-I, $21.3 \mathrm{~cm} / \mathrm{hen}$ for MFC-II and 26.7 $\mathrm{cm} /$ hen for MFC-III. The results also showed that in MFCIII cages where the dustbath box was positioned on the upper tier, hens needed to jump up to the higher tier to perform dust bathing, so the hens in MFC-III cages showed significantly less dustbathing than hens in MFC-I cages. Although no difference was found in dustbathing between MFC-II and MFC-III, dustbathing in MFC-II was also lower than that in MFC-III. It is suggested that hens prefer a low positioned dustbath to a higher located dust bath box. Nest allowance in this study was same for all furnished cages, but in MFC-III cages where two small nest boxes were provided the hens performed more nesting behavior than the hens in the other furnished cages. This may indicate that higher nesting for the hens in MFC-III is probably due to the low competition for nest.

In this study the hens in furnished cages performed more walking and less standing than in furnished cages. This may be due to the provision of a perch that promoted activity so that standing was less and walking was more. Also, the stocking density may be another important factor that restrains hens' activity. The results of this study showed that stocking density affected socializing and preening behavior of hens. And it suggested that low stocking density (MFC-I, -II, and -III) seemed to result in more socializing and preening behavior in hens than high stocking density as in SFC and CC. It also may indicate hens in low stocking density cages feel more comfortable than in high stocking density cages. Despite head-shaking being considered as anxiety behavior and increasing of this behavior reflecting a higher level of anxiety (Mendl, 1999), in this study headshaking was not found different between two cage types or between the furnished cages. Appleby et al. (2004) also suggested that, in furnished cages, the normal behaviors such as foraging, dustbathing, perching and feather-pecking were increased compared with $\mathrm{CC}$ cages. Furthermore, preening, wing-lifting and scratching are considered as comfort behavior (Pickel et al., 2010), thus the comfort behavior in furnished cages should be more prevalent than in CC (Appleby et al., 2004). In this study, increased preening, socializing, scratching and escaping behaviors occurred in hens in furnished cages and the layout of furnishings also seemed affect these behaviors as well since there was significantly higher preening and scratching but less feather-pecking by the hens in MFC-III than in SFC, MFC-I and MFC-II. Based on the results, the hens in MFCIII may feel more comfortable than the hens in other furnished cages. In this study feather-pecking did not show the effect by cage type, although Rodenburg et al. (2005) believe that hens in furnished cages have more opportunities to hide (perches, tiers) and space to escape, which can let them avoid feather-peckers. Our results did not prove it.

\section{Welfare of laying hens in different furnished cages}

It has been reported that the provision of perches and substrates in furnished cages may reduce the feather damage to hens (Braastad, 1990; Abrahamsson and Tauson, 1997). In CC, a hen's feathers are easily damaged because of the abrasion by cages and space limitation for combing feathers (Appleby et al., 1988). In this study, our results were in agreement with the above assumption. The results also suggested that higher stocking density could contributed to a worse feather condition as feather condition was downgraded as stocking density was increased from SFC to MFC-III. While Tactacan et al. (2009) reported no cage type effect on feather score between the birds in conventional and furnished cages, only that better wing feather coverage was found for hens in CC. The discrepancy between the two studies may be due to the furnished cage design and layout which varied for this study not stocking density.

Appleby et al. (2002) found a perch can improve claw conditions, and the claw condition of hens in furnished cages was better than hens in CC. In our study, although perch was available in all furnished cages, difference in claw score was found between cage types where claw condition in MFC-II and MFC-III cages was better than SFC and MFC-I cages. The difference between the two groups of cages was space which was larger for MFC-II and MFC-III cages than for SFC and MFC-I cages, and the hens in MFC-II and MFC-III had higher perching behavior than those in SFC and MFC-I cages. Thus, the results suggested perching is very important for hens' claw condition.

In this study, the hens in furnished cages showed better gait score than the hens in CC. In furnished cages, because of the larger space and existence of perch, hens performed more walking and perching, and less standing behaviors which could exercise the muscle and bone of hen's legs, as a result, the leg or claw condition was improved. Conversely, the hens in CC performed more standing and less walking potentially because of the narrow space, which eventually induced a lower gait score.

Tonic immobility duration is a common indicator to evaluate fear in poultry (Gallup, 1979). In this study the CC 
hens tended to be more fearful than hens in furnished cages. Tanaka et al. (1993) reported that increasing environmental enrichment can reduce the fear in hens. Our results agreed with this observation.

\section{CONCLUSION}

Hens in furnished cages showed more active behaviors and had better feather coverage, claw condition, gait condition and less fear than CC cages. The furnished cage design affected both behavior and welfare states of hens. Overall, MFC-III cage design was better than SFC, MFC-I, and MFC-II cage designs.

\section{CONFLICT OF INTEREST}

We certify that there is no conflict of interest with any financial organization regarding the material discussed in the manuscript.

\section{ACKNOWLEDGMENTS}

We would like to thank the Natural Science Foundation of China (NSFC) for its financial support to this study (No. 31172246/C170110).

\section{REFERENCES}

Abrahamsson, P. and R. Tauson. 1997. Effects of group size on performance, health and birds' use of facilities in furnished cages for laying hens. Acta. Agric. Scand. A-Anim. Sci. 47:254-260.

Albentosa, M. J. and J. J. Cooper. 2004. Effects of cage height and stocking density on the frequency of comfort behaviours performed by laying hens housed in furnished cages. Anim. Welf. 13:419-424.

Appleby, M. C., G. S. Hogarth, J. A. Anderson, B. O. Hughes, and C. T. Whittemore. 1988. Performance of a deep litter system for egg production. Br. Poult. Sci. 29:735-751.

Appleby, M. C. and B. O. Hughes. 1995. The Edinburgh modified cage for laying hens. Br. Poult. Sci. 36:707-718.

Appleby, M. C., J. A. Mench, and B. O. Hughes. 2004. Poultry behaviour and welfare. CABI Publishing, Wallingford, UK.

Appleby, M. C., A. W. Walker, C. J. Nicol, A. C. Lindberg, R. Freire, B. O. Hughes, and H. A. Elson. 2002. Development of furnished cages for laying hens. Br. Poult. Sci. 43:489-500.

Barnett, J. L. and G. M. Cronin. 2005. Welfare of laying hens in furnished cages. Australian Egg Corporation Limited, North Sydney, Australia. AECL Project No: DAV-197A.

Blokhuis, H. J., T. Fiks Van Niekerk, W. Bessei, A. Elson, D. Guémené, J. B. Kjaer, G. A. Maria Levrino, C. J. Nicol, R. Tauson, C. A. Weeks, and H. A. Van De Weerd. 2007. The LayWel project: Welfare implications of changes in production systems for laying hens. World Poult. Sci. J. 63:101-114.

Braastad, B. O. 1990. Effects on behaviour and plumage of a key- stimuli floor and a perch in triple cages for laying hens. Appl. Anim. Behav. Sci. 27:127-139.

Cordiner, L. S. and C. J. Savory. 2001. Use of perches and nestboxes by laying hens in relation to social status, based on examination of consistency of ranking orders and frequency of interaction. Appl. Anim. Behav. Sci. 71:305-317.

Dawkins, M. S. 1999. The role of behaviour in the assessment of poultry welfare. World Poult. Sci. J. 55:295-303.

Directive, E. U. 1999. Council Directive 99/74/EC of 19 July 1999 laying down minimum standards for the protection of laying hens. Official Journal of the European Communities 53-57.

Gallup, G. G. 1979. Tonic immobility as a measure of fear in domestic fowl. Anim. Behav. 27:316-317.

Guinebretière, M., H. Beyer, C. Arnould, and V. Michel. 2014. The choice of litter material to promote pecking, scratching and dustbathing behaviours in laying hens housed in furnished cages. Appl. Anim. Behav. Sci. 155:56-65.

Gvaryahu, G., E. Ararat, E. Asaf, M. Lev, J. I. Weller, B. Robinzon, and N. Snapir. 1994. An enrichment object that reduces aggressiveness and mortality in caged laying hens. Physiol. Behav. 55:313-316.

Lindberg, A. C. and C. J. Nicol. 1997. Dustbathing in modified battery cages: Is sham dustbathing an adequate substitute? Appl. Anim. Behav. Sci. 55:113-128.

Martin, P. and P. Bateson. 2007. Measuring Behaviour: An Introductory Guide. Cambridge University Press, Cambridge, UK.

Mendl, M. 1999. Performing under pressure: Stress and cognitive function. Appl. Anim. Behav. Sci. 65:221-244.

Nicol, C. J., A. C. Lindberg, A. J. Phillips, S. J. Pope, L. J. Wilkins, and L. E. Green. 2001. Influence of prior exposure to wood shavings on feather pecking, dustbathing and foraging in adult laying hens. Appl. Anim. Behav. Sci. 73:141-155.

Pickel, T., B. Scholz, and L. Schrader. 2010. Perch material and diameter affects particular perching behaviours in laying hens. Appl. Anim. Behav. Sci. 127:37-42.

Pohle, K. and H. W. Cheng. 2009. Comparative effects of furnished and battery cages on egg production and physiological parameters in White Leghorn hens. Poult. Sci. 88:2042-2051.

Rodenburg, T. B., F. A. Tuyttens, B. Sonck, K. De Reu, L. Herman, and J. Zoons. 2005. Welfare, health, and hygiene of laying hens housed in furnished cages and in alternative housing systems. J. Appl. Anim. Welf. Sci. 8:211-226.

Shimmura, T., Y. Eguchi, K. Uetake, and T. Tanaka. 2007. Behavior, performance and physical condition of laying hens in conventional and small furnished cages. Anim. Sci. J. 78:323-329.

Struelens, E., F. A. Tuyttens, L. Duchateau, T. Leroy, M. Cox, E. Vranken, J. Buyse, J. Zoons, D. Berckmans, F. Odberg, and B. Sonck. 2008. Perching behaviour and perch height preference of laying hens in furnished cages varying in height. Br. Poult. Sci. 49:381-389.

Tactacan, G. B., W. Guenter, N. J. Lewis, J. C. RodriguezLecompte, and J. D. House. 2009. Performance and welfare of laying hens in conventional and enriched cages. Poult. Sci. 88: 698-707.

Tanaka, T., T. Ozaki, T. Watanabe, H. Tanida, and T. Yoshimoto. 

1993. Effects of perches on behavior and performance of
caged hens. Japanese Poult. Sci. 30:183-189.

Wall, H., R. Tauson, and K. Elwinger. 2004. Pop hole passages and welfare in furnished cages for laying hens. Br. Poult. Sci. 45:20-27.
Wall, H., R. Tauson, and K. Elwinger. 2008. Effects of litter substrate and genotype on layers' use of litter, exterior appearance, and heterophil:lymphocyte ratios in furnished cages. Poult. Sci. 87:2458-2465.

Weeks, C. A. and C. J. Nicol. 2006. Behavioural needs, priorities and preferences of laying hens. World Poult. Sci. J. 62:296-307. 